\title{
Use of Lactobacillus fermentum for Improving Fermentation Degree of Smallholder Dried Cocoa Beans
}

\author{
Ariza Budi Tunjung Sari*1), N.A. Febrianto ${ }^{1)}$, Misnawi ${ }^{1)}$, and Teguh Wahyudi ${ }^{1)}$ \\ ${ }^{1)}$ Indonesian Coffee and Cocoa Research Institute, Jember 68118, East Java, Indonesia \\ *Corresponding author: ariza.bts@gmail.com \\ Received: 26 September 2019/ Accepted: 17 November 2019
}

\begin{abstract}
Cocoa beans produced from smallholder farming in Indonesia, are renowned for their low quality as a consequence of omitting fermentation. The unfermented beans are characterized with higher number of slaty and full purple cotyledons besides lower quality of chocolate aroma and flavor. Lactobacillus fermentum (LF) is one of the naturally available microorganisms in cocoa fermentation. LF culture had been reportedly successful in enhancing fermentation of fresh cocoa beans, however its effects on dried unfermented beans has not been investigated. This study aimed to evaluate the ability of LF culture in improving fermentation degree and sensory quality of dried unfermented beans. LF culture at concentration $5 \% \mathrm{w} / \mathrm{w}$ was added into dried cocoa beans under moist condition and incubated for four days. Treated beans were sun dried and evaluated for slaty and purple appearance on the nibs, as well as defects and sensory quality. This study reports a significant decrease in the proportion of slaty and purple beans in the treated groups either in smaller $(30 \mathrm{~kg})$ or in the larger $(150 \mathrm{~kg}) \mathrm{scales}$. The mouldy bean number surged, compared to in the untreated one. Its sensory profile obtained higher scores on the quality chocolate flavor which was due to stronger intensity. The quality of bitterness and astringency were also improved, due to lower intensity. It is concluded that LF culture could be used for improving the physical and sensory qualities of cocoa beans from smallholder farmers.
\end{abstract}

Keywords: Cocoa, smallholder, fermentation, Lactobacillus fermentum, sensory

\section{INTRODUCTION}

Indonesia is one of the main producing countries for cocoa. Its rank in the world production declines due to decreasing supply. The problem stems from aging trees, climate change, and conversion to other crops. In addition, Indonesian cocoa bean suffers from poor commercial image, caused by high number of unfermented beans and low chocolate flavor (Rifin, 2013). The unfermented beans might be an attribute found distinctively in Indonesian cocoa beans. In other producing countries such as Ivory
Coast, Ghana, and Ecuador, fermentation is indispensable step in cocoa bean production, considering its critical role in chocolate flavor formation.

Fermentation facilitates the development of chocolate aroma precursors while eliminating bitter and astringent tastes. It is a combination of microbiology and enzymatic processes occur on the pulp and inside the bean. Microorganisms taking place during the course of fermentation are mainly yeasts, lactic acid bacteria and acetic acid bacteria. Numbers of studies across producing countries had 
consistently reported the presence of Saccharomyces cereviseae, Lactobacillus fermentum, and Acetobacter pasteurianus (Ardhana \& Fleet, 2003; Camu et al., 2008; Papalexandratou et al., 2013). Among them, Lactobacillus fermentum (LF) gained interests due to its spontaneous growth during cocoa fermentation, wide availability, thermal and ethanol tolerance, as well as inhibitory property against mycotoxin producing fungi (de Melo Pereira et al., 2012; Ghazvini et al., 2016; Ruggirello et al., 2019).

Starter cultures for cocoa fermentation had been developed and effective application in fresh cocoa beans had been reported (Romanens et al., 2019). However, in Indonesia, availability of fresh beans for fermentation is challenging. In some region, such as in Java, cocoa trees are grown as yard plants in few numbers. The harvest are not done simultaneously, thus fresh beans for fermentation are scarcely provided. Once pod is opened, beans are scattered on bamboo tray and dried under the sun without prior fermentation. The dried unfermented beans are collected and sent to local trader once the quantity of $1-2 \mathrm{~kg}$ is reached. Consequently, dried unfermented beans predominate the supply chain (Nabhani et al., 2015).

Treatment is required to improve the quality of farmer's grade beans. In the previous study, LF culture at concentration $5 \%$ of bean weight had been successfully applied in conventional fermentation in small scale practice (Misnawi et al., 2017). The current study aims to investigate LF potential on improving the quality of dried unfermented cocoa beans. During the trial, beans are incubated with LF culture for four days followed by sun drying. The evaluation was made on physical and sensory quality of the dried treated beans. The physical quality inspection put special interest on the fermentation degree. Furthermore, treated beans were assessed for their sensory quality, comprising several attributes such ase chocolate aroma and flavor, caramel, cream, astringent, bitter, sweet, as well as acid notes.

\section{MATERIALS AND METHODS}

Lactobacillus fermentum (LF) isolate from Indonesian Culture Collection of LIPI was innoculated in MRS media and grown further in skim milk media. The liquid culture was then immobilized in pre-sterilized wheat flour. The final population in dry culture was $10^{7} \mathrm{CFU} / \mathrm{g}$ (Misnawi et al., 2017).

Untreated group representing smallholder quality was prepared from fresh cocoa beans that were sun-dried without prior fermentation. For the experiment, untreated beans were moistened (moisture content approximately 20\%) then incubated with LF inoculant at concentration $5 \%$ for 4 days. Incubation was done on $30 \mathrm{~kg}$ and $150 \mathrm{~kg}$ beans to represent small and larger scales respectively. Subsequently, treated beans were sundried until moisture content $7 \%$.

The degree of fermentation was determined by means of cut test. Three hundred beans were cut length-wise on the narrow side using a pruning shear, and the interior part is exposed against white surface. The color of beans was inspected visually and classified into gray (slaty), full purple, partly purple and brown. Full purple differs from partly purple when the proportion of purple areas are greater than half of bean surface. Gray and full purple beans are considered unfermented (BSN, 2010).

Upon cut test, beans with signs of germination, mould infection and insect infestation are separated and the percentage was calculated. Germinated bean is indicated from a hole in the bottom part of the bean, and mould infection is known from the presence of mycelium in the inner part of the bean. Meanwhile, insect infestation is indicated by 
insect body parts or grainy particles inside the bean (BSN, 2010).

Preparation of samples for sensory evaluation constituted of removing bean shells, roasting, and grinding. The roasting step was carried out at $116^{\circ} \mathrm{C}$ for 23 minutes (Farah et al., 2012). Roasted nibs were ground using kitchen miller to produce cocoa liquor. Liquor samples were tested by trained panelists from Indonesian Coffee and Cocoa Research Institute. Sensory attribute comprised chocolate aroma and flavor, caramel, cream, sweet, nut, bitter and astringent notes. The score was given for the quality of each attribute ranging from 0-2 (none to mild), 3-4 (weak), 5-6 (moderate), 7-8 (strong), and 9-10 (overpowering).

\section{RESULTS AND DISCUSSION}

\section{Fermentation Degree and Physical Quality}

Fermentation is essential for the development of hydrophobic amino acids and reducing sugars, both are precursors of chocolate aroma. It is started with pulp degradation by yeasts followed by growth of lactic acid and acetic acid bacteria. The products of microbial metabolism, such as ethanol, lactic acid and acetic acid, trigger bean death that leads to unification between polyphenol and polyphenol oxidase (De Vuyst \& Weckx, 2016). The event induces polyphenol degradation, turning bean color from purple to brown while eliminating the bitter and astringent properties. Omitting fermentation like in farmer practices, result in weak chocolate flavor paired with strong bitterness and astringency. The visual appearance of unfermented bean is gray (slaty) or purple colored.

In the smallholder farming in Indonesia, the typical practice of cocoa bean handling is started with harvesting, pod opening, bean extraction and drying. Fermentation is not a popular process among farmers, and interestingly a market for unfermented beans had already established in Indonesia (Nabhani et al., 2015). Therefore, dried unfermented beans has been an fairly average quality (FAQ) for Indonesian beans.

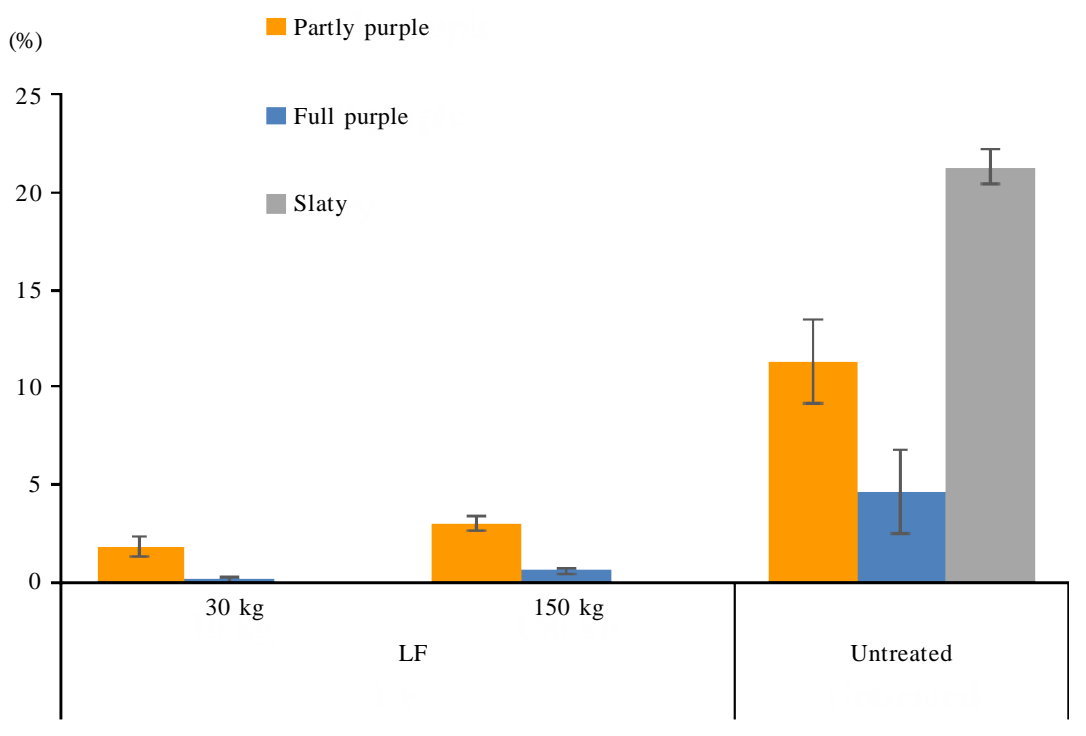

Figure 1. Percentage of slaty, full purple, and partly purple beans following treatments with additional Lactobacillus fermentum culture in the small $(30 \mathrm{~kg})$ and larger $(150 \mathrm{~kg})$ scales, as compared with farmer's grade beans (untreated) 
In this study, the dried unfermented beans were incubated in moist condition with additional LF culture. Moistened beans were expectedly providing favorable environment for LF, besides stimulating reactivation of endogenous enzyme in the nib. In the previous study, it has been shown that rehydration could resume activities of enzymes of cocoa nibs (Misnawi et al., 2002).

The trial showed that beans from LFtreated groups, either in small scale $(30 \mathrm{~kg})$ and larger scale $(150 \mathrm{~kg})$ incubations had obtained significantly $(\mathrm{p} \leq 0.05)$ lower number of slaty and full purple beans (Figure 1). The partly purple beans are considered as fermented one according to Indonesian National Standard for cocoa beans (BSN, 2010). Meanwhile, the untreated beans showed high number of slaty and full purple beans. The trial indicates that LF incubation had triggered polyphenol degradation that is marked with changing bean color from gray and purple into brown.

Unfortunately, the treatment had significantly increased number of mouldy beans, due to high moisture content caused from addition of LF liquid culture (Figure 2). The mouldy bean number exceeded SNI criteria which is $4 \%$ for the lowest grade. The material prepared from untreated beans had been containing high percentage of mouldy beans which was exacerbated during LF incubation. Even though attributed with anti-mycotoxin property, LF did not succeed to protect beans from mould growth. Higher concentration might be required to perform anti-fungal activity (Ghazvini et al., 2016; Ruggirello et al., 2019).

\section{Sensory Characteristic}

As expected from skipping fermentation, the precursors of chocolate flavor were underdeveloped and the liquor produced low chocolate quality. This was found in the untreated beans indicated by lower score in the chocolate flavor. Treatment with LF had successfully enhanced chocolate flavor quality and its complementary attributes such as caramel and sweetness.

The bitter and astringent attributes support the hypothesis that polyphenol degradation occurs during LF incubation. Score of bitterness and astringency in the treated groups were better than in the untreated one. The score indicates the quality of attribute which

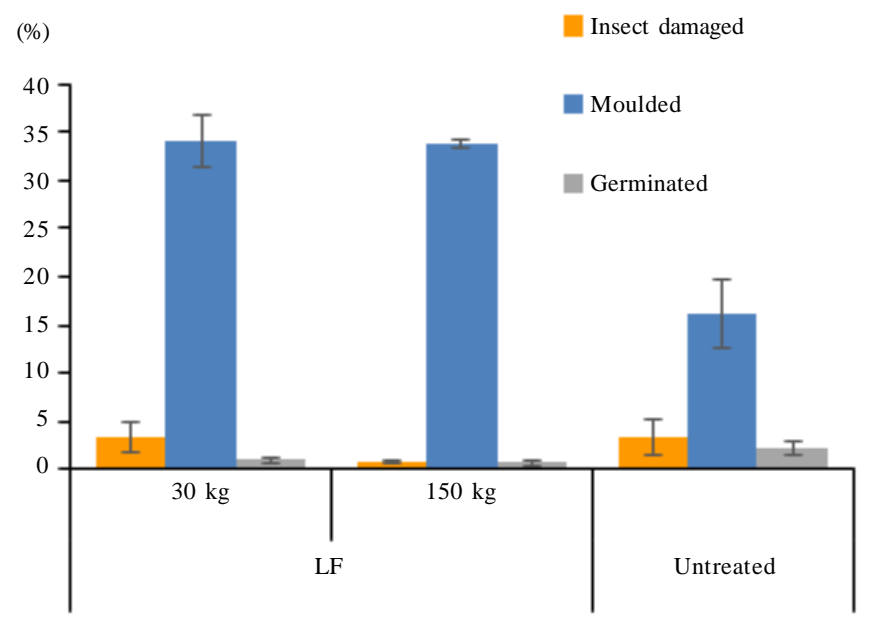

Figure 2. Percentage of defective beans including insect damaged, germinated and mouldy beans, following treatments with additional Lactobacillus fermentum culture in the small $(30 \mathrm{~kg})$ and larger $(150$ $\mathrm{kg}$ ) scales, as compared with farmer's grade beans (untreated) 


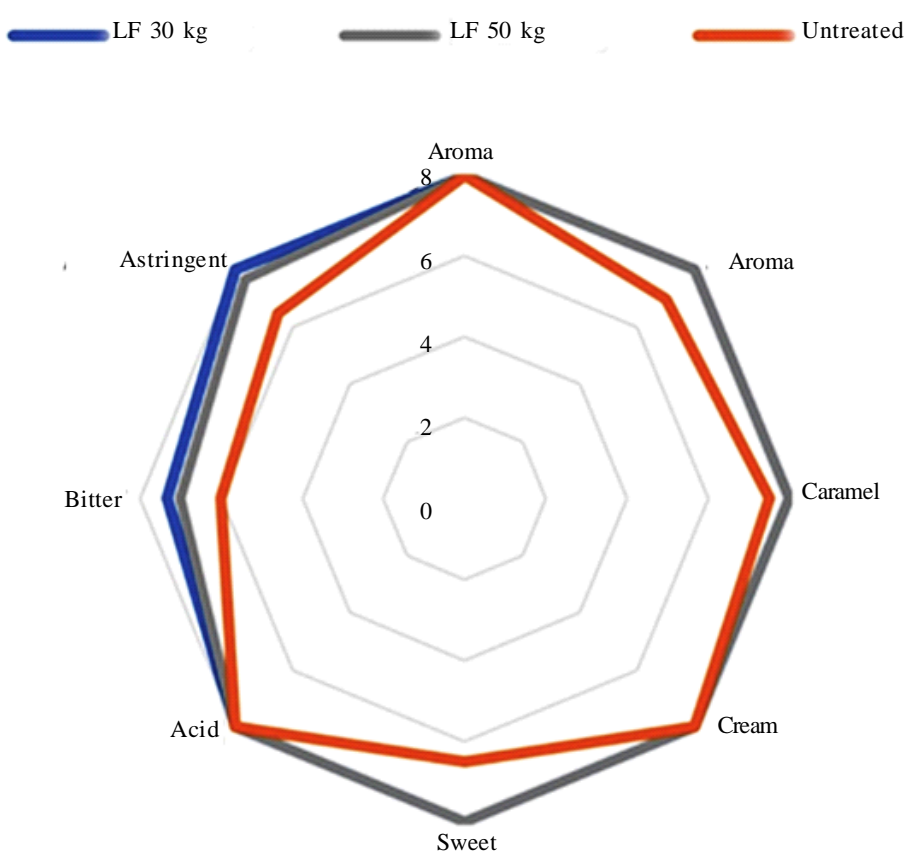

Figure 3. Sensory profile of cocoa liquor prepared from roasted beans, following treatments with additional Lactobacillus fermentum culture in the small (LF $30 \mathrm{~kg}$ ) and larger (LF $150 \mathrm{~kg}$ ) scales, as compared with farmer's grade beans (untreated)

is positively or negatively correlated with intensity. In terms of chocolate aroma, flavor, sweetness and caramel, higher score will be obtained following intense presence. On the other hand, for bitter, astringent and acid attributes, lower intensity generally lead to higher score of quality. Therefore in this study, higher score for the quality of bitterness and astringency was due to lower intensity.

Acidity is brought by organic acids from two sources; the pulp and bacteria. Cocoa pulp contains citric acid, that is metabolized into lactic acid. Acetic acid is produced from ethanol, as further process of sugar metabolism (De Vuyst \& Weckx, 2016). Since there is no pulp in the dried bean treatment, it is not surprising if acidity score was not changed after LF incubation.

Acidity is one of the factors that influence cocoa quality. Papalexandratou et al. (2019) suggested citric acid as compound characterizing fine flavor cocoa from Nicaragua, by exerting fruity notes. Additionally, in a chemometrics study conducted by Gil et al. (2019), lactic acid was assigned as one of several indicators of fermented cocoa. Lactic acid is generally undesired in chocolate industry because it has strong and persistent note that requires alkaline addition during processing. Therefore, the finding that LF did not affect acidity in cocoa is important for further utilization of LF in cocoa bean processing.

\section{CONCLUSIONS}

Lactobacillus fermentum (LF) is a potential bioactive agent for improvement of dried unfermented beans produced from common practice in smallholder farming. Higher degree of fermentation as well as flavor quality were obtained by incubating dried unfermented beans with LF inoculant. Nevertheless, the problem with mouldy beans needs further investigation. 


\section{REFERENCES}

Ardhana, M.M. \& G.H. Fleet (2003). The microbial ecology of cocoa bean fermentations in Indonesia. International Journal of Food Microbiology, 86, 87-99.

BSN (2010). Standar Nasional Indonesia SNI 2323:2008 Amandemen 1:2010 Biji Kakao. Badan Standardisasi Nasional. Jakarta.

Camu, N.; T. De Winter; S.K. Addo; J.S. Takrama; H. Bernaert \& L. De Vuyst (2008). Fermentation of cocoa beans: influence of microbial activities and polyphenol concentrations on the flavour of chocolate. Journal of the Science of Food and Agriculture, 88, 2288-2297.

De Melo Pereira, G.V.; M.G.D.C.P. Miguel; C.L. Ramos \& R.F. Schwan (2012). Microbiological and physicochemical characterization of small-scale cocoa fermentations and screening of yeast and bacterial strains to develop a defined starter culture. Applied Environmental Microbiology, 78, 5395-5405.

De Vuyst, L. \& S. Weckx (2016). The cocoa bean fermentation process: From ecosystem analysis to starter culture development. Journal of Applied Microbiology, 121, 5-17.

Farah, D.M.H.; A.H. Zaibunnisa; J. Misnawi \& S. Zainal (2012). Effect of roasting process on the concentration of acrylamide and pyrizines in roasted cocoa beans from different origins. APCBEE Procedia, 4, 204-208.

Ghazvini, R.D.; E. Kouhsari; E. Zibafar; S.J. Hashemi; A. Amini \& F. Niknejad (2016). Antifungal activity and aflatoxin degradation of Bifidobacterium bifidum and Lactobacillus fermentum against toxigenic Aspergillus parasiticus. The Open Microbiology Journal, 10, 197.

Gil, M.; Y. Jaramillo; C. Bedoya; S.M. Llano; V. Gallego; J. Quijano \& J. LondonoLondono (2019). Chemometric approaches for postharvest quality tracing of cocoa: An efficient method to distinguish plant material origin. Heliyon, 5, 1-12.
Misnawi; S. Jinap; S. Nazamid \& B. Jamilah (2002). Activation of remaining key enzymes in dried under-fermented cocoa beans and its effect on aroma precursor formation. Food Chemistry, 78, 407-417.

Misnawi.; A.B.T. Sari; N.A. Febrianto; R.S. Adiandri; F. Fahrizal \& Fahrurrozi (2017). Improvement of small scale cocoa fermentation using Lactobacillus fermentum as starter culture. Pelita Perkebunan, 33, 203-210.

Nabhani, I.; A. Daryanto; M. Yassin \& A. Rifin (2015). Can Indonesia cocoa farmers get benefit on global value chain inclusion? A literature review. Asian Social Science, 11, 288.

Papalexandratou, Z.; T. Lefeber; B. Bahrim; O.S. Lee; H.M. Daniel \& L. De Vuyst (2013). Hanseniaspora opuntiae, Saccharomyces cerevisiae, Lactobacillus fermentum, and Acetobacter pasteurianus predominate during well-performed Malaysian cocoa bean box fermentations, underlining the importance of these microbial species for a successful cocoa bean fermentation process. Food Microbiology, 35, 73-85.

Papalexandratou, Z.; K. Kaasik; L.V. Kauffmann; A. Skorstengaard; G. Bouillon; J.L. Espensen; L.H. Hansen; R.R. Jakobsen; A. Blennow; L. Krych; J.L. Castro-Mejía \& D.S. Nielsen (2019). Linking cocoa varietals and microbial diversity of Nicaraguan fine cocoa bean fermentations and their impact on final cocoa quality appreciation. International Journal of Food Microbiology, 304, 106-118.

Rifin, A. (2013). Competitiveness of Indonesia's cocoa beans export in the world market. International Journal of Trade, Economics and Finance, 4, 279.

Romanens, E.; S.F. Leischtfeld; A. Volland; M.J.A. Stevens; U. Kraehenmann; D. Isele; B. Fischer; L. Meile \& S.S. Miescher (2019). Screening of lactic acid bacteria and yeast strains to select adapted anti-fungal co-cultures for cocoa bean fermentation. International Journal of Food Microbiology, 290, 262-272. 
Ruggirello, M.; D. Nucera; M. Cannoni; A. Peraino; F. Rosso; M. Fontana; L. Cocolin \& P. Dolci (2019). Antifungal activity of yeasts and lactic acid bacteria isolated from cocoa bean fermentations. Food Research International, 115, 519-525.

$* * 0 * *$ 